\title{
Quantification beyond expenditure
}

\author{
The use of energy expenditure thresholds for quantifying energy poverty is a widely used approach, particularly \\ within the Global North. New research from Hong Kong confirms that this method risks overlooking important \\ housing and climate-related factors.
}

\section{Harriet Thomson}

nergy poverty occurs when a

household is unable to attain adequate levels of essential energy services in the home (such as cooling, use of appliances and lighting), and is known to impact over 1 billion households worldwide, including within wealthier European countries often considered immune to significant energy issues $^{1}$. The COVID-19 pandemic has powerfully demonstrated the importance of domestic energy services, arising from increased reliance on home working and home schooling, and an amplified need for healthcare-related energy access ${ }^{2}$. However, despite decades of research pointing to energy poverty as a condition that is distinct from other forms of poverty, there is no commonly agreed definition, and consequently, a multiplicity of measurement approaches. Writing in Local Environment, Annie On-ni Yip and colleagues from the Hong Kong Baptist University use Hong Kong as a case study to develop a new multidimensional framework that attempts to capture the wider complexities of energy poverty ${ }^{3}$.

Yip and team use data from five in-depth household case studies and 14 semi-structured interviews to develop a new theoretical framework, principally based on the energy vulnerability approach by Bouzarovski and Petrova ${ }^{1}$ that understands energy poverty as a temporally and spatially dynamic phenomenon underpinned by six vulnerability factors. Yip and team combine this approach with household responses (such as reducing consumption), and impacts (on health, relationships, education and dignity). In so doing, they bring into conversation important factors that are often absent from the measurement of energy poverty, such as energy needs and practices. Hong Kong offers a unique context for a case study due to the unusual legal-political factors arising from ubiquitous subdivided rental apartments, in combination with extreme hot weather conditions. Yet, to date, there have been relatively few studies of energy poverty emerging from this region.

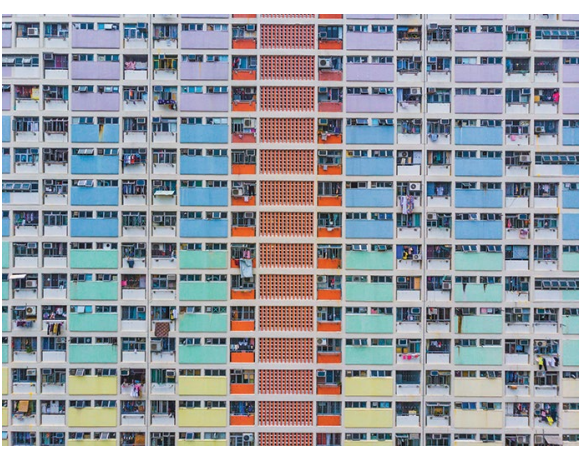

Credit: Yin Wenjie/Getty Images

Taking the lived experience of households as their central lens, Yip and team demarcate some of the ways in which energy poverty in Hong Kong is markedly different from western European countries. In Hong Kong, there is significant need for space cooling, and health dangers of hot summer nights. In contrast, key factors driving energy poverty in western European countries are gas and electricity prices, which have risen at significantly faster rates than inflation in most countries during the past two decades, and poor energy efficiency standards. Nevertheless, there are also points of connection. For instance, Yip and team refer to 'hidden energy poverty' in relation to households who under-consume energy as a mechanism for coping with vulnerability to energy poverty. This term finds resonance within the European context, and has been increasingly studied since the European Commission's EU Energy Poverty Observatory created a monitoring indicator in 2018 for capturing abnormally low energy expenditure compared to national medians ${ }^{4}$.

Yip and colleagues also draw attention to the unique housing quality issues that exist within Hong Kong, resulting from the widespread practice of illegally subdividing apartments to meet the huge demand for affordable housing. Along with concerns about safety and quality of living, the authors highlight issues around non-functional windows (which reduces opportunities for natural ventilation), overheating due to overcrowding and the legal loophole that allows landlords to profit by setting energy tariffs at significantly higher rates than those set by utility companies. The latter point corresponds with earlier work around the legal and political ambiguities that have combined to create heightened energy vulnerability within England's multiple occupancy housing sector ${ }^{5}$, and is likely to exist in other privatized housing markets, but as yet is an under-explored area in the energy poverty literature.

Despite the unique conditions of the Hong Kong context, the theoretical framework presented by Yip and team is limited by the fact that it centres upon the prevailing European triad of high energy prices, low household incomes and poor housing quality. This matters because the triad has been widely criticized for leading to overly technical policy responses that fail to recognise social aspects. Moreover, these three central factors do not fully capture the specific drivers identified within the Hong Kong case, such as extreme climate, lack of regulation concerning minimum property sizes and poor external air quality (which discourages households from opening windows).

Yip and team recognise that single indicator approaches to energy poverty measurement are flawed, particularly for their inability to capture important housing and climate-related factors. They also critique the ineffectiveness of mainstream energy expenditure-based indicators, which would fail to classify some of the households in their study as energy poor, despite clear evidence to the contrary emerging from the lived experiences documented. As a next step, it would be interesting to explore the extent to which their framework could be operationalized for quantification purposes, given that statistical indicators are an important and necessary part of the policy landscape ${ }^{6}$. This is a critical challenge that 
energy poverty researchers have yet to crack: how to reflect the diversity and complexity of energy poverty in statistical form, without flattening in such a way that important but difficult to measure factors are silenced ${ }^{7}$.

Energy poverty is a rapidly moving field, with increasingly diversified viewpoints from across the academic spectrum, and from different parts of the world, to which this paper makes an important contribution. While it is unfortunate that the authors have not engaged with contemporary literature published in recent years, the study by
Yip and colleagues nevertheless shines a spotlight on important and novel issues, whilst serving to highlight the importance of considering energy poverty complexly, and moving beyond the limitations of prevailing indicators.

Harriet Thomson (D) $₫$

School of Social Policy, University of Birmingham, Birmingham, UK.

凶e-mail:h.thomson@bham.ac.uk

Published online: 7 August 2020

https://doi.org/10.1038/s41560-020-00682-9
References

1. Bouzarovski, S. \& Petrova, S. Energy Res. Soc. Sci. 10 31-40 (2015).

2. Castán Broto, V. \& Kirshner, J. Nat. Energy 5, 419-421 (2020).

3. Yip, A. O., Mah, D. N. \& Barber, L. B. Local Environ. 25, 473-491 (2020).

4. Thema, J. \& Vondung, F. EPOV Indicator Dashboard: Methodology Guidebook (Wuppertal Institut für Klima, Umwelt, Energie GmbH); https://www.energypoverty.eu/sites/default/files/ downloads/observatory-documents/20-07/epov_methodology_ guidebook.pdf

5. Bouzarovski, S. \& Cauvain, J. Space Polity 20, 310-329

6. Thomson, H., Bouzarovski, S. \& Snell, H. Indoor Built Environ. 26, 879-901 (2017).

7. Sareen, S. et al. Glob. Transit. 2, 26-36 (2020).

Competing interests

The author declares no competing interests. 